старшеклассниками у детей дошкольного возраста, а также способствует становлению сознательности и ответственности у учащихся общеобразовательных учреждений. Таким образом, обеспечивается преемственность между дошкольной и школьной ступенями образования.

Просветительская программа «Мир и Я: курс экологического просвещения для детей старшего дошкольного возраста» является ответом на запрос общества и позволяет реализовать работу по национально-культурному компоненту, стимулирует детей к познанию окружающей природной среды.

Необходимо отметить, что методические и дидактические материалы курса неоднократно принимали участие в конкурсах различных уровней и получали благодарности от руководителей образовательных организаций и социальных некоммерческих организаций.

При анализе деятельности дошкольников по итогам учебного года, было отмечено, что ребята стали лучше разбираться в вопросах экологического характера, а именно, улучшились способности выстраивания причинно-следственных связей, появились практические навыки и умения самостоятельно посадить растение в землю, провести наблюдение, пользоваться инструментами и микроскопом и т.д. Таким образом, реализация данной образовательной практики на региональном уровне позволит создать надежный фундамент экологической культуры и экологического сознания подрастающего поколения.

$$
* * *
$$

1. Козлова, Е.В. Развитие познавательных способностей дошкольников на занятиях по экологии посредством использования информационно-коммуникационных технологий / Е.В. Козлова // Социальная сфера, управление и экономика: актуальные проблемы и перспективы. - 2016. - С. $129-131$.

2. Х Хаустова, С.Д. Экология и дошкольник / С.Д. Хаустова // Вестник научных конференций. - 2015. № 3-6 (3). - С. 166-168.

3. Яковлева, Е.Н. Дошкольник и экология / Е.Н. Яковлева // Наука и образование: новое время. 2017. - №1 (18). - С. 218-223.

\title{
Вельдина Ю.В. \\ Использование онлайн-переводчиков как средство обучения иностранному языку: преимущества и недостатки
}

Пензенский государственный технологический университет

(Россия, Пенза)

doi: $10.18411 / \mathrm{lj}-07-2021-120$

\section{Аннотация}

В статье рассматривается проблема целесообразности и эффективности использования онлайн-переводчиков при изучения иностранного языка. Актуальность выбранной темы обусловлена тем, что в настоящее время наблюдается растущая активность интереса к переводу иностранных текстов через онлайн-переводчики, так как они бесплатны, удобны и не требуют установки. В данной статье автором рассматриваются особенности перевода иностранных текстов при помощи онлайнпереводчиков, приводятся примеры наиболее часто используемых онлайнпереводчиков и выделяются их преимущества и недостатки.

Ключевые слова: онлайн-переводчик, машинный перевод, функциональная возможность, эффективное средство, качество перевода.

\section{Abstract}

The article deals with the problem of expediency and effectiveness of using onlinetranslators when we are learning a foreign language. The relevance of the chosen topic is 
because at present there is a growing interest in the translation of foreign texts through onlinetranslators, as they are free, convenient and do not require installation. In this article, the author considers the peculiarities of foreign text translation using online-translators, gives examples of the most commonly used online translators and highlights their advantages and disadvantages.

Keywords: online-translator, machine translation, functionality, effective tool, quality of translation.

Изучая иностранный язык, часто приходится прибегать к помощи онлайнпереводчика. Переводить текст, сидя за огромным словарем, отыскивая и подбирая нужные слова, кажется «долгим и скучным занятием» в последнее время для большинства людей. К тому же переведя отдельные слова, их нужно будет сложить в целостные предложения, в то время как онлайн-переводчик за считанные минуты выдает уже полностью переведенный текст. Но в этом легком на первый взгляд и доступном переводе бывает сложно понять смысл текста, поэтому важно и нужно хорошо ориентироваться во всем изобилии онлайн-переводчиков и выбрать именно такой, который будет не только переводить текст, а еще, таким то образом, способствовать изучению иностранного языка.

Что же такое онлайн-переводчик? История появления, так называемого машинного перевода, берет свое начало еще с древних времен, когда общение разноязычных народов стало напряженным. Они не могли сотрудничать и вести торговлю, потому что не понимали друг друга. Именно тогда уже начали задумываться о кодировании символов и букв для того, чтобы создать единый язык. Идея создания специальной машины для перевода с одного языка на другой пришла в голову известном математикам 17 века Готфриду Вильгельму Лейбницу и Рене Декарту, но развитие науки шло медленно и ученые не смогли воплотить это в жизнь. Спустя много лет, за разработку взялся ученый Чарльз Бэббидж, которому удалось спроектировать первую во всем мире вычислительную машину. А уже в 1947 году, математик Уоррен Уивер работал над переводом текста с одного языка на другой с помощью промежуточного языка, таким образом, и появился машинный перевод. Дальнейшее развитие перевода с помощью вычислительной машины произошло в 1954 году. Тогда перевод был проведен на IBM-70, программа которого включала в себя всего 250 слов, шесть правил грамматики и лимит составлял 49 предложений. Идея использования электронно-вычислительных машин для перевода оказалась довольно проста и довольно быстро получила огромную популярность [2].

Уже с начала 80-х годов компьютеры заполонили весь мир и стали доступными, поэтому машинный перевод стал экономически выгодным и по времени перевода превосходил человека. Компьютерные системы и программы совершенствовались, вместе с тем и улучшалось качество переводимых текстов машинным переводом. С тех пор многие проблемы машинного перевода так и остались нерешенными и требуют постоянного усовершенствования.

Онлайн-переводчики нашего времени, основанные на машинном переводе - это довольно доступные и в большинстве случаев бесплатные программы, которые можно с легкостью найти в интернете. Любой переводчик за короткий промежуток времени выдает готовый перевод с одного языка на другой с помощью специальной компьютерной программы. Онлайн-переводчик вытеснил книги-словари, потому что для него не нужно искать место в сумке, в любой ситуации он всегда находится под рукой [1].

Экономия времени - это не единственная цель создания такого переводчика. Главной задачей является доступность человека без знания иностранного языка пользоваться иноязычными публикациями и уменьшить влияние языкового барьера. 
На сегодняшний день Интернет предлагает большое множество онлайн-сервисов для перевода, отличающихся друг от друга своими функциональными возможностями и качеством самого перевода. Популярными считаются сервисы «Google Translate», «Yandex Translate», «Translate.ru», «Abby Lingvo». Эти онлайн-переводчики имеют большое преимущество по быстроте и точности перевода, а также эффективны при изучении иностранного языка. Рассмотрим вкратце, что же представляют собой вышеназванные онлайн-переводчики [3].

«Abby Lingvo» является системой электронных словарей. Первая версия выпущена в 1990 году. Включает в себя более 200 словарей на разных языках. В нем можно не только перевести слова, но и узнать их значение, посмотреть примеры из текстов, узнать о его сочетании с другими частями речи, посмотреть все грамматические формы этого слова и многие другие функции [5].

Онлайн-переводчик «Google Translate» является самым популярным среди всего многообразия интернет переводчиков, включая в себя более 108 языков и использует только собственное программное обеспечение. Данный онлайн-переводчик появился 28 апреля 2006 года. Его сервис позволяет перевести всю веб-страницу и одновременно искать информацию, переводя ее на другой язык. Но даже такой отличный по своим характеристикам переводчик имеет недостатки и ограничения. Он выдает большинство верно переведенных фраз и предложений, но все же весь предложенный текст переводит не точно. Так же в числе недостатков предложение нецензурных слов как вариант разговорного слогана и большая часть переведенного текста с любого другого языка выдается в английской форме, что значительно меняет смысл текста [6].

«Yandex Translate» - это онлайн-переводчик, разработанный российскими программистами и выпущенный компанией Яндекс. Он был создан 22 марта 2011 года и включает в себя 98 языков. Система сервиса имеет самообучаемый алгоритм и, анализируя тысячи переведенных статей, составляет собственные словари, что помогает строить логический смысл переводимого текста. Еще одна немаловажная особенность, способность прослушивания произношения переводимых слов. Так или иначе, этот онлайн-переводчик так же имеет свои недостатки, но со временем все совершенствуется и улучшается качество перевода [4].

Лучшим по праву считается онлайн-переводчик «Translate.ru», который был выпущен 6 марта 1998 года российской компанией «PROMT». На сегодняшний день эта система включает в себя 22 языка. Переводя слово, сервис открывает статью из словаря с другими примерами данного слова. Так же на выбор предлагаются различные тематики, для улучшения качества перевода и возможность прослушивания произношения на переводимом языке. Интересно, что даже такой многопользовательский сервис имеет недостаток, но в отличие от других онлайнпереводчиков, всего один - ограничение символов в окне перевода (доступно только 3000), но стоит только зарегистрироваться, этот параметр повышается до 10000 символов [7].

Без сомнения, быстрота перевода относится к положительным характеристикам онлайн-переводчиков, но есть и обратная сторона медали, которой заключается в том, что онлайн-переводчик достаточно выдает низкое качество перевода, смысл которого, без последующего редактирования будет понятен не сразу.

Поэтому следует выделить преимущества и недостатки использования онлайнпереводчиков при изучении иностранного языка.

Среди преимуществ следует отметить следующее:

- свобода доступа (если установить приложение, можно пользоваться без выхода в интернет);

- быстрота перевода (возможность загрузки полного текста);

- абсолютно бесплатное использование (не запрашивает ввод средств для дальнейшего перевода); 
— не требует дополнительных знаний пользователя (пользоваться может любой человек, не имеющий даже начальных знаний языка);

- перевод на все языки мира (легко переключается с одного языка на другой, без потери смысловых качеств).

Однако, несмотря на все преимущества, есть и существенные недостатки:

- большая погрешность перевода;

- необходимость выхода в интернет;

- на изучение языка никакого влияния не оказывает.

Прогресс не стоит на месте, постоянно что-то меняется, становится лучше и качественнее, так обстоит дело и с онлайн-переводчиками. Их идея состояла и состоит в том, чтобы упростить перевод, сделать его быстрее, не тратя время на пролистывание бумажного словаря. Нельзя говорить, что одно лучше другого, у каждого из них своя функция. Как известно, мозг - самый ленивый орган, который нужно постоянно нагружать работой. И листая все тот же словарь, бегая глазами по страницам и отыскивая слова, процесс изучения иностранного языка все же совершенствуется, т.к. глаза напрямую связаны с мозгом и то, что они увидели, тут же откладывается в памяти. В то время как онлайн-переводчики настолько усовершенствованы, что уже можно даже не вводить на клавиатуре слова или текст, нужно просто сфотографировать и загрузить, без задействования мозговой деятельности, и через считанные секунды результат будет готов, но в памяти ничего не отложится.

Таким образом, если человек, например, находится в чужой стране без знания языка, онлайн-переводчик будет помощников и его использование будет на пользу. Но говоря про изучение иностранного языка эти сервисы оказывают лишь «медвежью услугу», не более того.

$$
* * *
$$

1. Жарков В.В. Онлайн-переводчики и их качество. - Переводчик, Москва. - 1997 г.

2. Кулагина О.С. О современном состоянии машинного перевода // Математические вопросы кибернетики, вып. 3, М.: Наука. - 1991. - С. 5-50.

3. Машинный перевод [сайт]. URL: https://ru.wikipedia.org > wiki >

4. Яндекс. Переводчик [сайт]. URL: https://ru.wikipedia.org > wiki >

5. ABBYY_Lingvo [сайт]. URL: https://ru.wikipedia.org > wiki >

6. Google_Переводчик [сайт]. URL: https://ru.wikipedia.org > wiki >

7. Translate [сайт]. URL: https://ru.wikipedia.org > wiki >

\section{Вилкова А.В. ${ }^{1}$, Ковалев О.Г. ${ }^{2}$, Сухарева Е.В. $^{3}$ \\ Оперативно-розыскные меры профилактики пенитенциарной преступности несовершеннолетних}

${ }^{1}$ Научно-исследовательский институт ФСИН России (Россия, Москва)

${ }^{2}$ Псковский филиал Академии ФСИН России

(Россия, Псков)

${ }^{3}$ Санкт-Петербургский университет МВД России (Россия, Санкт-Петербург)

doi: $10.18411 / \mathrm{j}-07-2021-121$

\section{Аннотация}

В статье речь идет об особенностях использования комплекса педагогических и оперативно-розыскных мер, направленных на профилактику пенитенциарной преступности несовершеннолетних, реализуемых на разведывательном, основном и контрольном этапах, характеризующихся применением специальных педагогических 